The risk to the patient and the fetus if the uterus ruptures is serious and even when mother and baby survive the mother's future childbearing capacity is usually lost. Clearly, uterine hyperstimulation must always be avoided and oxytocin and prostaglandin should not generally be used in the grandmultipara or the patient who has previously had a caesarean section. If it is felt necessary to use these agents then continuous monitoring of labour is essential, especially if epidural analgesia is to be employed.

${ }^{1}$ O'Driscoll, K., Proceedings of the Royal Society of Medicine, 1966, 59, 65. 2 Department of Health and Social Security, Confidential Enquiries into Maternal Deaths in England and Wales, 1966. London, H.M.S.O., 1972 ${ }^{3}$ Delfe, E., and Eastman, N. J., Canadian Medical Association fournal, 1945, 52, 376.

4 Kerr, J. M. M., Operative Obstetrics, 8th edn., ed. J. C. Moir and P. R. Mayerscough, p. 854. London, Baillière, Tindall and Cassell, 1971.

5 Crawford J. S., Lancet, 1974, 1, 361.

Department of Obstetrics and Gynaecology, King's College Hospital, London SE5 9RS

M. BRUDENELL, F.R.C.o.G., F.R.C.s., Consultant Obstetrician

S. CHAKRAVARTI, F.R.C.S., M.R.C.o.G., Registrar

\section{Busulphan Toxicity Syndrome caused by Chlorambucil}

The well-recognized syndrome of busulphan toxicity comprises diffuse interstitial fibrosis, cutaneous pigmentation, and symptoms resembling adrenal cortical insufficiency. ${ }^{1}$ These complications tend to occur after relatively long-term treatment and this paper records two patients who developed toxicity during treatment with chlorambucil for chronic lymphocytic leukaemia for three years.

\section{Case Histories}

A.B., aged 60, had responded well to corticosteroid treatment and was on a low dose of prednisolone for three years. But chlorambucil was prescribed when signs of deterioration developed. After a year his weight began to fall and he again showed clinical deterioration. Chlorambucil and prednisolone and he again showed clinical deterioration. Chlorambucil and prednisolone were increased. Despite regression of the leukaemia the patient got worse
(see figure). Endeavours to identify a coexistent malignancy were un(see figure). Endeavours to identify a coexistent malignancy were un-
successful. At this clinical nadir the platelet count was $7 \times 10^{9} / 1$, the successful. At this clinical nadir the platelet count was $7 \times 10^{9} / 1$, the
bone marrow was densely lymphocytic, but normal haemapoietic cells were represented. A dose of two $\mathrm{mg}$ vincristine was given and within a week the platelet count rose to $50 \times 10^{9} / 1$. This could either be attributed to vincristine or to recovery from chlorambucil myelosuppression. But the count fell again and complications attributed to vincristine toxicity developed-urinary obstruction and the syndrome of inappropriate A.D.H. secretion.

C.D. was 67 when she was prescribed chlorambucil for chronic lymphocytic leukaemia. There was a rapid haematological response, so chlorambucil was stopped for one year and restarted for submandibular lymph node enlargement. After taking two mg chlorambucil daily for three months she became weak and breathless. Chlorambucil was again withheld and the becane wiratory symptoms and radiological signs dith respiratory syme following months. Twenty months later chlorambucil was prescribed again, and she had repeated episodes of breathlessness, attributed to lower respiratory produced a particular susceptibility to acute respiratory infections.

\section{Discussion}

The pulmonary changes originally described in association with busulphan treatment ${ }^{1}$ have since been seen to complicate the course of patients receiving other cytotoxic drugs. ${ }^{2}$ Fatal interstitial pulmonary changes have been described in four patients receiving chlorambucil for chronic lymphocytic leukaemia. ${ }^{3}$ The more remarkable syndrome of multiple toxic side effects associated with busulphan administration has not been described during chlorambucil treatment, or indeed with other cytotoxic drugs.

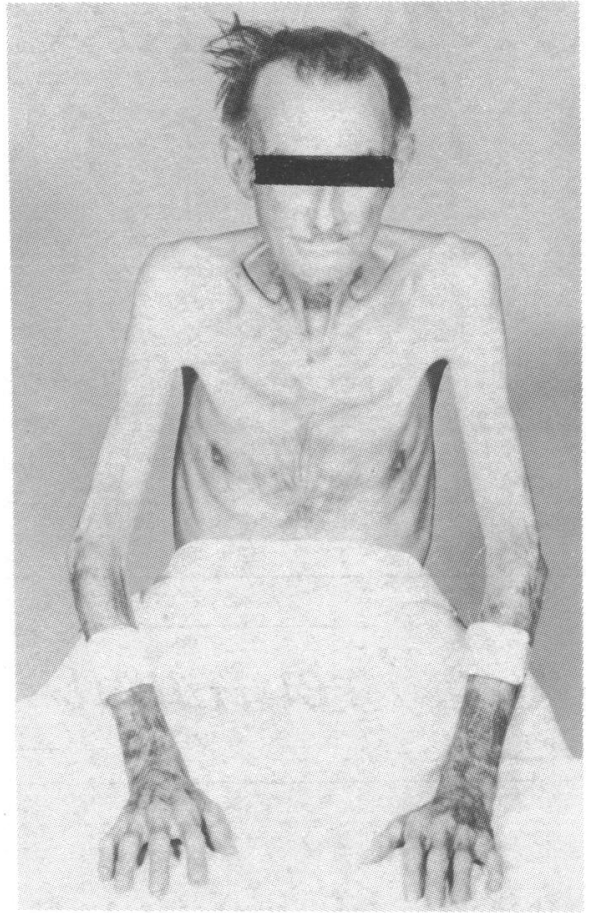

Gross emaciation of patient while in leukaemic regression.

Though the term "interstitial pulmonary fibrosis" has been used to describe the lung changes seen, the histological features indicate alveolar cell proliferation with morphological abnormalities. The fact that the pulmonary changes are reversible suggests that clinical dysfunction precedes the development of fibrosis. Thus the reaction may not be predominantly fibrosis and the alternative descriptive term "pulmonary alveolar cell proliferation" may be preferable. Pulmonary function studies performed in patients during early stages of cytotoxic treatment displayed severe abnormalities in the absence of clinical symptoms or radiographic changes in the lungs. ${ }^{4}$

Patient A.B. has died. Necropsy showed nothing to contradict the conclusion that he was suffering untoward consequences of chlorambucil treatment. Had the drug administered been busulphan there would have been no hesitation in accepting this view.

These cases show that busulphan-associated complications may occur during chlorambucil administration and should be borne in mind as a possible consequence of treatment with cytotoxic drugs in general. As Dameshek and Gunz said: "It is of extreme importance to recognise the beginning of the syndrome since the drug(s) can be discontinued and the patient may recover; if this is not done, an irreversible situation with extreme wasting culminating in death will develop."s

1 Kyle, R. A., et al., Blood, 1961, 18, 497 . Diseases of Children, 1970, 120, 337 .

3 Rubio, F. A., New England fournal of Medicine, 1972, 287, 1150.

4 Prentice, G., Allen, N. C., and Rose, M. S., unpublished observations, 1974.

5 Dameshek, W., and Gunz, F., in Leukaemia, 2nd. edn., p. 544. New York, Grune \& Stratton, 1964.

Department of Haematology, St. George's Hospital, London SW1 7 OQT

M. S. ROSE, PH.D., M.R.C.PATH., Senior Lecturer 